\title{
DESCRIÇÃO DE UMA VIVÊNCIA DE ENSINO ORIENTADA PELA GESTALTPEDAGOGIA
}

\author{
Description of a Teaching Experience in Gestaltpedagogy \\ Descripcion de una Vivencia de Enseñanza Orientada por la Gestaltpedagogia \\ Juliana Arrais de Morais Moreira \\ LudyMila Pimenta FERreira \\ Virginia Elizabeth Suassuna Martins Costa
}

\begin{abstract}
Resumo: O presente artigo relata uma experiência de prática de ensino no curso de Licenciatura em Psicologia, e tem por objetivo geral relacionar o exercício da docência em forma de regência em uma Escola-campo com a teoria e a prática da Gestaltpedagogia, tendência inovadora da Educação e da Psicologia. A proposta do artigo é apresentar a vivência dos princípios gestálticos aplicados à pedagogia, enfatizando a forma como o contato era estabelecido e mantido no aqui-e-agora, assim como a expansão das fronteiras-de-contato. A prática na escola-campo foi realizada em 22 horas-aula com exposições orais dialogadas, apresentação de filmes temáticos, atividades e discussões em grupo. Foi possível experienciar que a aprendizagem dos conteúdos teóricos nessa perspectiva exige contato no aqui-e-agora, responsabilidade, atenção frente às necessidades dos alunos, abstenção de juízos e conceitos pré-estabelecido, e a expansão das fronteiras-de-contato, tanto para professores quanto para os alunos, construindo uma relação intersubjetiva.
\end{abstract}

Palavras-chave: Gestaltpedagogia; Aqui-e-agora; Fronteiras-de-contato; Relação Intersubjetiva.

Abstract: The present article tells a teaching experience in the Psychology course and it has the aim to relate the teaching in a school with the theory and practice of Gestaltpedagogy, that is a new tendency in Education and Psychology. The article will present the experience with the gestalt principles applied to the education emphasizing how the contact and the contact frontier expansion were set and kept on here and now. The experience at school was executed by 22 classes with discussions, movie presentations and activities in group. In this perspective, the content learning requires the contact on here and now, the responsability, the atention to the students necessities without judgement and prejudice, and the contact frontier expansion of students and teachers, to built an intersubjectiveness relation.

Keywords: Gestaltpedagogy; Here and Now; Contact Frontier; Intersubjectiveness Relation.

Resumen: El presente artículo relata una experiencia de la práctica de enseñanza en el curso de Licenciatura en Psicología, y tiene por objetivo primordial relacionar el ejercicio de la docencia en forma de regencia en una Escuela-campo con la teoría y la práctica de la Gestaltpedagogia, una tendencia innovadora de la educación y de la Psicología. La propuesta del artículo es presentar la vivencia de los principios gestálticos aplicados a la Pedagogía, enfatizando la forma como el contacto era establecido y mantenido en lo aquí-y-ahora, así como la expansión de las fronteras de contacto. La práctica en la escuela-campo fue realizada en 22 horas-aula con explanaciones orales dialogadas, presentación de películas temáticas, actividades e discusiones en grupos. Se puedo contactar que el aprendizado de los contenidos teóricos en esta perspectiva exige le contacto e lo aquí-y-ahora, o arcar con responsabilidad, la atención ante las necesidades de los alumnos, sin juicios y conceptos préestablecidos y la expansión de las fronteras de contacto, tanto de profesores como también de alumnos, construyendo una relación ínter-subjetiva.

Palabras-clave: Gestaltpedagogia; Aquí-y-ahora; Fronteras de Contacto; Relación Ínter-subjetiva.

\section{Fundamentos Teóricos da Gestaltpedagogia}

Desde a Antiguidade, havia uma preocupação e conscientização da Sociologia com respeito à importância da educação para a vida social. Para alguns autores, como Comte, Marx e Durkheim, a educação implica uma forma de difusão de idéias, com grande papel no restabelecimento da ordem social. Os objetos de estudo da Sociologia da Educação são os aspectos sociais do fenômeno educativo, tanto nas suas relações externas (religião, política, eco- nomia) e internas - relativo às unidades que compõem o sistema educacional (Ferreira, 1993).

De acordo com Mello (2000), durante os anos 80 e 90, do século passado, o Brasil deu passos significativos para a universalização do acesso ao ensino fundamental obrigatório, tais como o investimento na qualidade da aprendizagem desse nível escolar. Essa caminhada foi necessária em virtude das expectativas educacionais de ampliação do reconhecimento e da importância da educação na sociedade do conhecimento. Em resposta a essas expectati- 
vas, desde 1980, os sistemas de ensino público e privado vêm passando por processos de reforma educacional, em âmbito estadual, local ou mesmo nas unidades escolares, em busca de novos modelos de aprendizagem.

Dentro do contexto educacional, a Pedagogia é a ciência que visa à descrição e a explicação da natureza da educação em uma determinada sociedade, seus determinantes, seus processos e seus modos de atuação, bem como os meios apropriados para a formação de indivíduos (Libâneo, 1985).

No processo de desenvolvimento educacional, em 1977, surgiu uma nova atitude na Pedagogia, denominada Gestaltpedagogia. De acordo com Burow \& Scherpp (1985), a Gestaltpedagogia é um termo que abrange conceitos pedagógicos que se orientam pelas idéias teóricas e práticas da Psicologia da Gestalt.

A Psicologia da Gestalt focalizou a experiência subjetiva e a exploração da consciência. Seus promotores Max Wertheimer, Wolfgang Köhler e Kurt Koffka, sustentam que a percepção de formas constitui uma propriedade inata do sistema visual. Quando há um objeto situado contra um fundo, ele destaca-se, como figura (Burow \& Scherpp, 1985). A figura não é parte isolada do fundo, ela existe e se revela nele. O desenrolar das ações é uma dinâmica entre ambos, ou seja, a figura é algo que está sendo da maior importância naquele momento, porém pode se tornar fundo em questões de segundos e viceversa (Ribeiro, 1985).

Ribeiro (1985) salienta que além da figura-fundo, os conceitos de todo-parte e aqui-e-agora são fundamentais para a compreensão da Psicologia da Gestalt. O todo é, na realidade, um fenômeno global e, pode ser compreendido pela globalidade, que cria sua natureza interior ou lhe confere consciência. O todo-parte está em íntima relação com a experiência, que "só chega até nós de modo completo, quando ela é experimentada como um todo, ainda que este todo seja apenas um esboço da realidade do ser como tal" (Ribeiro, 1985, p. 71). O mesmo autor assinala que o aqui-e-agora é um conceito holístico, que envolve totalidade, ao passo que a Gestalt é cheia e plena. Para Polster \& Polster (1979), a expressão aqui-e-agora não deve, contudo, ser entendida ao pé da letra, como se só fosse válida a experiência atual, pois também são válidos o passado e futuro quando se tornam atuantes.

Além da Gestaltpedagogia se basear nos conceitos da Psicologia da Gestalt, fundamenta-se também nos conceitos da Psicologia Humanista, cujas raízes espirituais e históricas remetem ao Humanismo, à Filosofia Existencial e à Fenomenologia, que serão descritos a seguir (Burow \& Scherpp, 1985).

Segundo Ribeiro (1985), o Humanismo designa uma concepção de mundo e da existência, que tem o homem como centro, como valor positivo, com a capacidade de se autogerir e de regular-se. Além disso, Burow \& Scherpp (1985) ressaltam que a Psicologia Humanista admite ser necessário conhecer toda a vida do ser humano, caso se queira entendê-lo como uma totalidade, e parte do princípio de que a pessoa sadia possui um objetivo final na vida. Para os autores da Psicologia Humanista, os princípios apresentados, sobretudo por Carl Rogers, contribuem para a aprendizagem com muitas idéias sensatas, estímulos e conceitos. Esse aplica a teoria de sua terapia centrada no cliente ao ensino escolar e à formação, à preparação, ao desenvolvimento e ao aperfeiçoamento do ser humano.

Em congruência com o Humanismo, a filosofia existencialista, obedece à crença de que o homem é um ser de auto-responsabilidade, de relação e permanentemente mutante (Ribeiro, 1985). Essa filosofia, de acordo com Burow \& Scherpp (1985), é dinâmica, ou seja, as pessoas estão sempre se refazendo e descobrindo a si mesmas, uma vez que há sempre novas possibilidades a serem exploradas. O Existencialismo compreende o ser humano como ser concreto, individual e relacional, ou seja, sempre um ser(estar)-no- mundo e ser(estar)-com-os-outros. Tem como proposta perceber o homem como um ser particularizado no seu modo de ser e de agir, concebendo-o como único no universo e individualizando-se com o encontro verdadeiro entre sua subjetividade e sua singularidade.

A compreensão do modo de existir que evidencia esse ser-no-mundo, em situação, colocado diretamente em contato com a existência, chama-se fenômeno, palavra grega derivada de um verbo que significa manifestar-se, aparecer (Ribeiro, 1985).

Bicudo (1999) refere-se à Fenomenologia como colaboradora da busca do sentido e atribuição dos significados aos fenômenos, tornando-se um excelente modo de trabalho na realidade escolar, pela possibilidade de trabalhar o real como ele é vivido no cotidiano. Em outras palavras, a Fenomenologia surge como método do Existencialismo e não parte de proposições lógicas ou de teorizações sobre o aluno, a escola, a atividade docente e a aprendizagem, mas considera alunos e professores no modo tal como estão no contexto escolar.

Dartigues (2005) enfatiza um dos conceitos que diferencia a Fenomenologia de outras ciências: a redução fenomenológica, que significa "colocar em suspenso" o conhecimento das coisas do senso comum e perceber a realidade tal qual ela se apresenta, percebendo o outro sem a contaminação de conceitos pré-existentes.

Na prática pedagógica, alguns princípios citados acima são reformulados, tais como: o princípio do aqui-eagora se torna o aprender no aqui-e-agora, a concentração sobre o contato, torna-se o aprender na fronteira-decontato com o conteúdo ou a vivência apresentada, o arcar com responsabilidade, com decisão consciente, o self-support, o reconhecimento do ser humano como um organismo digno de confiança e com potencial de possibilidades que o professor deve desenvolvê-los (Burow \& Scherpp, 1951).

A utilização de métodos e experimentos favorece o surgimento de outros princípios fundamentais para a apren- 
dizagem: o princípio do estímulo à consciência (awareness) centrado no objetivo de que todo ser humano possui capacidade de identificar de maneira integral e correta a totalidade de sua vivência em decorrência da consciência de si mesmo e do outro; o princípio da Gestalt fechada, que alerta para as amarras de energia que acontecem quando as Gestalts abertas prejudicam a ocupação com uma outra tarefa (Burow \& Scherpp, 1985).

No presente artigo, focalizou-se o interesse na forma como o contato era estabelecido e mantido no aqui-e-agora, assim como a expansão das fronteiras-de-contato.

\section{Contato e Fronteiras-de-contato}

Contato é um dos conceitos centrais e mais conhecidos da Gestalt. Segundo Perls (1977), o organismo tem tanta necessidade psicológica como fisiológica de contato. É por meio dele que cada pessoa tem a chance de se encontrar com o mundo exterior de uma forma provedora. O contato não se refere simplesmente à companhia de outra pessoa ou a um agrupamento. Ele só pode acontecer entre seres separados, sempre exigindo independência e sempre se arriscando a ser capturado na união. O ponto de partida é a realização de contato da pessoa consigo mesma, o que ocorre quando o contato acontece de forma consciente, com percepções até então evitadas. Ele se dá na fronteira, um ponto de encontro entre o eu e a percepção evitada, que se torna objeto de atenção.

Para Perls, Hefferline \& Goodman (1997), é na fronteira que os perigos são rejeitados, os obstáculos são ultrapassados e o que é assimilável é selecionado e apropriado. Aquilo que é selecionado e assimilado é sempre novo. $\mathrm{O}$ organismo sobrevive pela assimilação do novo, pela mudança e pelo crescimento.

É possível sentir a operação dos pensamentos ou sentimentos de uma outra pessoa, à medida que se tenha contatado suas próprias operações e se possa eximir-se da preocupação pessoal de como uma outra pessoa poderia perceber a mesma coisa (Polster \& Polster, 1979).

Polster \& Polster (1979) discutem seis tipos de fronteiras-de-contato: as fronteiras-do-eu, as fronteiras-do-corpo, as fronteiras-de-valor, as fronteiras-de-familiaridade, as fronteiras-expressivas e as fronteiras-de-exposição.

As fronteiras do ser humano, as fronteiras-do-eu, são determinadas pela gama das suas experiências de vida e por sua capacidade interna para assimilação de experiência nova ou intensificada. Dá-se ênfase ao poder que o indivíduo tem de criar a sua própria vida, que inclui o poder de reconhecer a adequação ao seu meio ambiente. O poder de fazer contato nunca pode ser inteiramente independente da escolha de ambientes ou da criação de novos ambientes.

As fronteiras-do-corpo referem-se às preferências das pessoas em relação a seus corpos. A consciência da sensação de algumas partes ou funções pode estar restringi- da ou limitada e permanece fora do conhecimento que elas têm de si mesma. Assim, essas pessoas ficam fora do contato com partes importantes delas mesmas.

As fronteiras-de-valor, geralmente são rigidamente estabelecidas, provavelmente por causa das pressões que elas sofrem, quando há necessidade de abandonar próprios padrões. Dessa maneira, deve-se aprender a expandir as fronteiras-de-valor para incluir a autodeterminação e abrir caminhos para soluções criativas.

Às vezes, o medo do desconhecido estabelece as fronteiras-de-familiaridade. As oportunidades permitem experienciar somente uma pequena porção das possibilidades que se apresentam nas vidas das pessoas, e limites de geografia ou de tempo restringem o contato com o novo ou não-familiar. Essas fronteiras são inevitáveis e parcialmente removidas com base no contato com situações e pessoas novas. No entanto, essa fronteira é estabelecida pelas próprias pessoas e pelo que não é familiar, quando há a recusa de contatar-se em virtude de um limite imposto.

Em relação às fronteiras-expressivas, deve-se ressaltar que os tabus contra o comportamento expressivo começam cedo, quando a criança ouve dos adultos: "não toque", "não se mexa”, "não chore”, "não se masturbe”, "não urine” e, assim, as fronteiras são delineadas. É ameaçador romper as fantasias que são estabelecidas para si mesmo, pois há o medo de perder a própria identidade. Todavia, no ato de eliminar antigas fronteiras-expressivas, é possível chegar a um senso aumentado do eu.

A fronteira-de-exposição também compartilha um terreno comum com todas as outras fronteiras. Entretanto, a relutância específica se manifesta em relação à pessoa ser observada ou reconhecida. Um indivíduo pode saber o que ele valoriza, pode expressá-lo e até desenvolver as ações apropriadas a ele, mas insiste em fazê-lo de maneira privada ou anônima. Outras pessoas podem não querer ser identificadas como cruéis, sedutoras, críticas, manipuladoras, exigentes, ingênuas, ad infinitum. A exposição é perigosa, seja ela exposição aos elementos, ao desprezo ou à exigência dos outros. É importante em relação ao desenvolvimento dessa fronteira a forma pela qual o exibicionismo interfere no crescimento pessoal.

Dentre as funções de contato, citadas por Polster \& Polster (1979), o olhar, o escutar, o tocar, o falar, o movimentar, o cheiro e o gosto, contribuem para um melhor contato intersubjetivo entre professor-aluno. O contato intersubjetivo é contemplado pelo ensino gestaltpedagógico que enfatiza a necessidade do professor desenvolver uma forma de se relacionar com o aluno.

\section{Ensino Gestaltpedagógico}

No ensino gestaltpedagógico, a aprendizagem ocorre com a interpretação de conteúdos psicológicos, e de matérias e didática específicas relacionadas aos conteúdos 
político-sociais. Essa nova forma de didática é importante em virtude da centralização na pessoa, dos princípios e métodos da Gestaltpedagogia, que envolvem aspectos específicos, psicológicos e político-sociais. $\mathrm{O}$ aspecto específico refere-se ao conteúdo de cada matéria, sua relação com o todo e a relação entre elas e o mundo dos alunos. $\mathrm{O}$ aspecto político-social compreende todas as condições em que o ensino ocorre, que influenciam tanto os alunos, quanto as instituições e os professores. $\mathrm{O}$ aspecto psicológico compreende os conteúdos de história de vida dos alunos, a dinâmica do grupo e sua situação atual individual. Dessa forma, é importante verificar como os alunos envolvidos na relação professor-aluno estabelecem contato consigo mesmos, com o professor e com o conteúdo (Costa, 2002).

Costa (2002) afirma que o ensino gestaltpedagógico pode ser melhor entendido quando são discutidos três pontos: um comportamento diferente do professor, o desenvolvimento da personalidade dos alunos e os métodos e princípios gestálticos. Mais especificadamente, podemse apresentar esses três aspectos que se seguem.

A Gestaltpedagogia exige um comportamento diferente do professor, portanto, é importante saber como se comporta um professor que utiliza a Gestaltpedagogia, pois a maioria das técnicas está relacionada com seu desenvolvimento pessoal. A modificação do seu comportamento deveria se orientar para a mudança da própria personalidade, que acontece na relação interpessoal com o aluno. Assim, leva-se em conta a relação intersubjetiva, que significa ver, aceitar e tratar o aluno como um ser humano, pontos fundamentais na sala de aula. Os educadores devem ter a possibilidade de um treino prático, de uma vivência própria, para crescer pessoal e profissionalmente. Portanto, a qualidade do professor determina a qualidade do aprendizado.

A Gestaltpedagogia objetiva o desenvolvimento da personalidade dos alunos, e esse desenvolvimento pressupõe uma mudança de comportamento do professor e implica novos objetivos e métodos de ensino. $\mathrm{O}$ contato indireto entre as pessoas precisa ser abolido em favor do contato direto, e o aluno deve ser visto como unidade existencial de corpo-alma-mente, em que o processo ensino-aprendizagem começa no atendimento às necessidades dos alunos e não na transmissão do conteúdo.

Os métodos e princípios gestálticos podem ser utilizados para alcançar tanto objetivos tradicionais, quanto novo. A fantasia projetiva, a técnica gestáltica da cadeira vazia e a percepção do aqui-e-agora são alguns métodos que podem ser utilizados.

Ribeiro (1994) ressalta que educar é tocar o ser como ele se apresenta, com suas exigências, com seu modo especial de estar no mundo, e não com base em pré-juízos, pré-conceitos ou de angústias. Diante desses desafios, este trabalho consiste em relacionar o exercício da docência em forma de regência em uma escola-campo com a teoria da Gestaltpedagogia, focalizando a forma como o contato foi estabelecido e mantido no aqui-e-agora, assim como a expansão das fronteiras-de-contato.

\section{Metodologia}

A prática pedagógica foi realizada em uma Escola Estadual situada na região central da cidade de Goiânia (GO), por meio de quatro horas de observação da escola-campo, seis horas de observação em sala de aula e 22 aulas ministradas em duas turmas de sétima série do ensino fundamental. No primeiro contato com a escola, as estagiárias apresentaram os objetivos do trabalho a ser realizado e o termo de consentimento, que foi assinado pela diretora da escola.

Os materiais utilizados durante a regência foram: onze planos de aula com os temas escolhidos pelos alunos; folha de cartolina, canetas, revistas, cola, tesoura, resma de papel chamex branco e colorido, fita crepe, giz, apagador, balões, espelho, vídeo-cassete, fita cassete, aparelho de som e CDs.

$\mathrm{Na}$ primeira aula, com o intuito de perceber as necessidades da turma, foi elaborado um levantamento de temas a serem abordados por meio de uma atividade em que os alunos iriam ajudar as professoras-estagiárias a escolher os melhores canais para a emissora de televisão que elas iriam criar. Quinze desenhos em formato de televisão foram impressos e colados em volta da sala com temas diversos e o título do programa. Para a escolha de temas, cada aluno escreveu em um papel, três assuntos que mais lhes chamaram a atenção e que julgaram ter maior audiência. Os temas eleitos foram trabalhados nas dez aulas consecutivas.

$\mathrm{Na}$ segunda aula, aprofundaram-se os temas mais escolhidos, ou seja, os alunos tiveram que perguntar ou escrever em papéis as dúvidas que tinham sobre esses temas, e as professoras-estagiárias comprometeram-se a respondê-las ao longo do semestre. Nessa mesma aula, os alunos fizeram um desenho de uma pessoa e escreveram: ao lado da cabeça, três pensamentos dessa pessoa; ao lado esquerdo da boca, uma frase que ela falara e da qual se arrependera; ao lado direito da boca, uma frase que ela gostaria de falar; ao lado esquerdo do peito (coração), três sentimentos; ao lado da mão esquerda, três coisas que gostaria de receber; ao lado da mão direita, três coisas que gostaria de oferecer; ao lado do pé direito, o que ela se propõe a realizar; e ao lado do pé esquerdo, aonde essa pessoa quer chegar. Essa atividade teve como objetivo despertar nos alunos a importância do autoconhecimento.

A terceira aula visou mudanças corporais na adolescência, na qual os alunos se aqueceram, desenhando os números (de zero a nove) com o corpo, direcionando a atenção para os movimentos e as sensações obtidas. A seguir, a turma foi dividida em grupos de cinco alunos, e cada grupo desenhou um corpo humano (feminino ou 
masculino), sem roupas. Em seguida, escreveram ao lado da cabeça, os pensamentos; ao lado do peito, os sentimentos; ao lado do corpo, as sensações; e ao lado dos pés, os comportamentos que mudaram da infância para a adolescência. O objetivo dessa atividade visou o conhecimento do próprio corpo e do sexo oposto para a compreensão das mudanças corporais que ocorrem na transição da infância para a adolescência, assim como os processos psicológicos envolvidos.

A aula seguinte se referiu à higiene e cuidados com 0 corpo. A professora-estagiária e os alunos simularam que estavam tomando banho, lavando-se e passando as mãos em todas as partes do corpo, para ressaltar a importância do contato consigo mesmo. Em seguida, dois casos fictícios de adolescentes foram lidos, e os alunos tiveram que encontrar soluções e propor sugestões para as mudanças na vida desses jovens. Nessa mesma aula, meninos e meninas tiveram que trocar de papéis, sentindo as mudanças corporais do sexo oposto, com o intuito de compreender e respeitar o processo de mudança do outro.

Na quinta aula, antes de abordar o tema sobre sexualidade e doenças sexualmente transmissíveis, as professoras-estagiárias trabalharam com os alunos o que uma pessoa é capaz de transmitir por meio dos pensamentos, sentimentos e atitudes, para depois trabalhar o que o corpo transmitia. Assim, a professora simulou que estava de mau humor e entrou na sala gritando, implicando com a outra professora e com alguns alunos. Após esse evento, foi pedido aos alunos que relatassem o que sentiram, o que imaginavam que estava acontecendo, e o que a professora transmitiu a eles. Logo, um papel foi entregue para que eles escrevessem o que transmitiam, o que gostariam de transmitir, o que as pessoas os transmitem e o que eles gostariam de receber das pessoas. Depois de uma discussão sobre as doenças de que os alunos tinham conhecimento, foi passado um filme sobre sexo, drogas e doenças sexualmente transmissíveis (DST), para que eles compreendessem a dimensão da auto-responsabilidade em relação às conseqüências de seus atos.

A sexta aula teve como objetivo tratar as relações de amizade e namoro, e foi realizada no pátio da escola. Para isso realizou-se uma brincadeira em que os alunos vivenciaram situações de lidar com o outro, buscando principalmente as soluções de problemas através da importância do diálogo. Primeiramente os alunos andaram em círculos e no decorrer da brincadeira, foram fazendo grupos de dois, e após, grupos de três até oito, de acordo com o que era pedido pelas professoras-estagiárias. Durante a brincadeira, frente ao comportamento dos alunos de puxarem outros colegas para seus grupos, foi proposto então uma discussão acerca de pensamentos, sentimentos, sensações e comportamentos de puxar e ser puxado, relacionando-os com o tema amizade e namoro, englobando também paixão e amor, influência de grupos, "ficar", traição, amor não-correspondido e fofocas. Em relação a fofocas, leu-se um depoimento em que informações fo- ram transmitidas de maneira errada, e os alunos puderam dar exemplos pessoais ressaltando o lado negativo da falta de diálogo.

$\mathrm{Na}$ aula seguinte, o tema referente às diferenças individuais, preconceito e religião foi discutido por meio de um filme que aborda diferentes percepções. Estimulou-se a turma a falar sobre os tipos de pessoas que sofrem preconceitos no Brasil e no mundo. Foi pedido aos alunos para que refletissem sobre situações em que foram vítimas de preconceitos e preconceituosos. No mesmo dia, foi tratada a importância do respeito ao limite do outro, por meio de uma atividade em que os alunos, em dupla, encostavam as duas palmas das mãos no ar, e ora uma pessoa empurrava, ora era empurrada. Ao passar do tempo, quem estivesse sendo empurrado (tendo seu limite ultrapassado) os braços ficariam cansados, pesados e doeria, porém de quem estivesse empurrando (entrando no limite do outro) não.

A oitava aula trabalhou a autopercepção da família. Os alunos escreveram o próprio nome por extenso, e fizeram colagens com palavras retiradas de revista, que caracterizavam cada nome e sobrenome. Ao final, houve uma discussão sobre características e valores positivos e negativos que eles herdaram de sua família, enfatizando que essa percepção poderia contribuir para o relacionamento deles com os pais.

Seguindo esse tema, a nona aula se referiu à relação entre pais e filhos. No início, os alunos ouviram a música "Pais e Filhos" da banda Legião Urbana, e refletiram sobre a própria família. Em seguida, a letra da música foi entregue aos alunos, e eles sublinharam partes com as quais se identificaram, de acordo com o momento que estavam vivenciando. Teve por objetivo permitir uma abertura aos alunos para refletirem sobre sua família, enfatizando pontos positivos e negativos, assim como o que poderiam fazer para resolver possíveis conflitos. Logo após, uma atividade de troca de papéis entre pais e filhos foi realizada. Foram pregados pedaços de papéis em volta da sala com nomes de lugares (igreja, bar, velório, show, festa em família, cinema, carnaval de rua, praça, aniversário do chefe do pai, clube, supermercado, casa, escola) e dividiu-se a turma em dois grupos: pais e filhos. No primeiro momento a professora pediu para cada "pai" pegar um filho e levar para um dos locais citados acima. No segundo momento foi feita a troca de papéis, ou seja, os pais se tornaram filhos, e vice-versa. A brincadeira foi utilizada pelas professoras-estagiárias para trabalharem os pensamentos, sentimentos, sensações e comportamentos vivenciados durante a atividade, para a compreensão da responsabilidade em cada papel.

A penúltima aula teve como tema o futuro profissional e, como objetivo, promover uma reflexão sobre o futuro. Antes de trabalhar o futuro profissional, foi abordada a vida pessoal dos alunos, discutindo sobre as diferentes bagagens que a pessoa leva para cada lugar, além de cada um ter vivências e histórias de vida diferentes. 
Assim, cada aluno recebeu uma mala de papel, refletiu sobre a bagagem que carregava naquele momento e escreveu quatro tópicos: "o que eu tenho e preciso (manter)"; "o que eu tenho e não preciso (lutar para retirar)"; "o que eu não tenho e preciso (lutar para conseguir)"; "o que eu não tenho e não preciso (não precisa buscar)". Logo depois, houve uma discussão sobre a relação das experiências pessoais com o futuro profissional, e os alunos tiraram dúvidas sobre vários tipos de profissão.

A última aula teve como objetivo promover uma integração dos temas discutidos por meio de atividades com música e balóes. No primeiro momento a professora colocou perguntas acerca dos temas discutidos durante o decorrer das aulas dentro de balões, que foram passados de aluno para aluno até que a música parasse, e o aluno que estivesse com o balão na mão teria que estourá-lo e responder a pergunta. A aula foi finalizada com uma atividade onde foi colocado um espelho dentro da caixa, e em que a professora-estagiária dizia que dentro da caixa havia a coisa mais importante de suas vidas, a solução de todos os problemas, que deveriam valorizar. Após a brincadeira levantou-se uma discussão acerca dos pensamentos, sentimentos, sensações e comportamentos surgidos.

Cada aula foi ministrada por uma estagiária, na qual a outra observava e anotava pontos relevantes que serviriam de feedback e que seriam relacionados com a teoria estudada.

Todos os materiais construídos em sala de aula pelos próprios alunos foram devolvidos a eles, por serem, sobretudo, atividades que trabalhavam conteúdos subjetivos, não cabendo às professoras-estagiárias avaliá-los.

\section{Discussão}

A partir da vivência na escola-campo e da teoria da Gestaltpedagogia faz-se necessária uma reflexão crítica da relação entre ambas, e alguns aspectos vivenciados na escola e retomados teoricamente foram descritos.

Na primeira aula, na qual se realizou o levantamento de temas, a atividade proposta foi importante para que o aluno entrasse em contato com as fronteiras-do$e u$ e refletisse sobre a sua vivência no aqui-e-agora. Eles puderam então escolher os temas e se expressar sobre o que gostariam que fosse abordado, além de assuntos surgidos no momento. De acordo com a teoria de Perls (1977), essa é uma forma consciente de obtenção de contato, no qual o ponto de partida é a realização de contato da pessoa consigo mesma. Além disso, Costa (2002) ressalta que o processo ensino-aprendizagem começa pelo atendimento às necessidades dos alunos e não pelo conteúdo, pois o ensino gestaltpedagógico baseia-se na vivência.

As fronteiras-do-corpo foram contatadas por meio de atividades que envolviam movimentos e reflexões, dire- cionando a atenção para as sensações, como na aula de mudanças corporais na adolescência, em que os alunos se aqueceram fazendo os números com o corpo e desenharam o corpo humano sem roupas. Além disso, os alunos entraram em contato com as fronteiras-do-eu ao refletirem sobre as modificações dos pensamentos, sentimentos, sensações e comportamentos ocorridos na transição da infância para a adolescência. Tendo por objetivo o conhecimento do próprio corpo e do sexo oposto os alunos puderam expandir suas fronteiras-expressivas rompendo tabus tradicionais adquiridos durante o desenvolvimento. De acordo com a teoria de Polster \& Polster (1979), as fronteiras-do-corpo possibilitam a consciência da sensação de algumas partes de seus corpos que estão limitadas pelos comportamentos expressivos, e no ato de eliminar antigas fronteiras-expressivas, é possível chegar a um senso aumentado do eu.

Levando em consideração que as diferenças de gênero masculino e feminino predominavam nas relações, percebeu-se a necessidade de uma atividade que promovesse a vivência da troca de papéis, enfatizando os pensamentos e sentimentos da pessoa do sexo oposto. Para Polster \& Polster (1979), isso é possível caso se tenha contatado suas próprias operações e possa eximir-se da preocupação pessoal de como uma outra pessoa poderia fazer a mesma coisa.

Foi observado que, no decorrer das aulas, os alunos adquiriram confiança em si, nos colegas e nas professoras-estagiárias. No início, a maioria deles preferia escrever perguntas e dúvidas em pedaços de papel, com receio de se expor e ser criticado, ou seja, participava indiretamente das aulas. Polster \& Polster (1979) confirmam que há certa dificuldade das pessoas entrarem em contato com a fronteira-de-exposição por medo de serem criticadas e identificadas como ingênuas, cruéis e sedutoras. O desenvolvimento das fronteiras-deexposição dos alunos foi possível na realização de atividades de leitura, dança, discussões orais dialogadas, apresentações em grupo e individual. Isso facilitou a participação direta, por meio de perguntas para sanar as dúvidas e esclarecer fatos pessoais relatados. $\mathrm{O}$ contato só pôde ocorrer porque as professoras-estagiárias também entraram em contato com suas fronteiras-deexposição, compartilhando opiniões e experiências, o que favoreceu a construção da relação intersubjetiva professor-aluno.

Dois fenômenos também ocorreram em conseqüência dessa relação. Havia grande resistência de um aluno em participar das aulas e integrar-se com a turma, até a penúltima aula, quando ele teve a oportunidade de experienciar o que seus colegas consideraram inédito, ou seja, uma auto-exposição. O segundo fenômeno foi a apresentação de um teatro elaborado e vivenciado pelos alunos, na qual representavam pais e filhos discutindo sobre drogas e gravidez na adolescência, enfatizando a importância do diálogo para esses tipos de conflitos. Isso serviu como 
feedback para as professoras, demonstrando um crescimento pessoal das mesmas.

Em relação às fronteiras-de-valor, percebeu-se que a maioria da turma conseguiu expandi-las, encontrando soluções criativas para as situações propostas durante as atividades. No entanto, foi observada certa rigidez em alguns alunos, ligada, sobretudo a valores religiosos. $\mathrm{Na}$ aula de drogas e doenças sexualmente transmissíveis, para que eles compreendessem a dimensão da auto-responsabilidade em relação às conseqüências de seus atos, as professoras-estagiárias enfatizaram que o ser humano é responsável por tudo que transmite, seja por pensamentos e sentimentos, seja pelo corpo, através de doenças. Após a aula, um aluno procurou as professoras-estagiárias para relatar sua insatisfação como o fato delas influenciarem negativamente o início de sua sexualidade e utilização de drogas. Frente a este fenômeno, através de uma discussão dialogada com a turma, foi possível confirmar que esta impressão não atingiu o todo, mas somente alguns alunos, da mesma religião, que relataram que tais assuntos não são permitidos em sua igreja. Polster \& Polster (1979) confirmam que os valores são rigidamente estabelecidos, pelas pressões que sofrem, quando há necessidade de abandonar próprios padrões.

O fenômeno referido acima, ainda assim, não deixou de gerar certa insegurança nas professoras-estagiárias, mas desta forma, buscaram o auto-suporte e ampliaram as próprias fronteiras como forma de enfretamento para as aulas seguintes. Para Costa (2002), o auto-suporte o coloca diante desta possibilidade de ser, de chamar para si mesmo as conseqüências de seus atos.

Outro ponto a ser ressaltado é que as professorasestagiárias instigaram a si mesmas e aos alunos a ultrapassarem a própria fronteira-de-familiaridade, buscando contato com o novo por meio da auto-responsabilidade e do diálogo consigo mesmo e com o outro. Tal fenômeno foi melhor desenvolvido nas últimas aulas, que abordaram temas sobre amizade, namoro, família e auto-estima. Pode-se afirmar que houve um melhor resultado em razão da intersubjetividade desenvolvida no decorrer das aulas, o que ele não teria sido obtido da mesma maneira, se esses temas fossem abordados nas aulas iniciais. Para Polster \& Polster (1979), as fronteiras-de-familiaridade são parcialmente removidas pelo contato com situações e pessoas novas.

Para entrar em contato com todas as fronteiras, as professoras-estagiárias tiveram que, principalmente, aceitar a Gestaltpedagogia e quebrar valores tradicionais pré-estabelecidos, modificando alguns comportamentos em sala de aula, tais como: utilizar planos de aula elaborados a partir da vivência e necessidade dos alunos, sem priorizá-los como figura, mas desenvolvê-los a partir dos fenômenos que surgiam, dando aos alunos autonomia e responsabilidade pelo conteúdo da aula. Tal atitude é confirmada por Costa (2002), ao dizer que o desenvolvimento da personalidade dos alunos pres- supõe uma mudança de comportamento do professor e vice-versa.

Mesmo com as mudanças de alguns comportamentos, é importante ressaltar que, inicialmente, as professorasestagiárias não consideravam as diferenças entre as duas turmas e utilizaram os mesmos planos e técnicas em ambas. A falha inicial, porém, foi percebida e, alguns planos foram modificados. Foi interessante perceber que o tema sobre preconceito, religião e diferenças individuais gerou bom desempenho em ambas as turmas, porém teve maior resultado na segunda turma, por ali haver uma aluna com Síndrome de Down, para o qual o preconceito era mais significativo. A teoria de Burow \& Scherpp (1985) tem como proposta ver o homem como um ser particularizado no seu modo de ser e de agir, concebendo-o como único no universo e individualizando-o, no encontro verdadeiro entre sua subjetividade e sua singularidade.

Além disso, a primeira turma era considerada pelos professores da escola-campo como a turma-problema. Entretanto, nas vivências, isso não foi percebido. Assim, as professoras-estagiárias tiveram o primeiro contato com os alunos, sem juízos e conceitos pré-estabelecidos, educando-os com base neles mesmos, suas exigências, seus modos especiais de estarem no mundo, como cita Ribeiro (1994). Também vai ao encontro da Fenomenologia, especialmente no que se refere à redução fenomenológica, que propõe a suspensão das atitudes, crenças e teorias, a fim de concentrar-se exclusivamente na experiência em foco, dado que esta se apresenta como a realidade para a pessoa (Dartigues, 2005).

Enfim, todas as atividades realizadas durante o semestre, que fizeram os alunos entrarem em contato e até mesmo ultrapassarem as fronteiras, foram consideradas formas extremamente criativas para o desenvolvimento de uma boa relação intersubjetiva e, conseqüentemente, o desenvolvimento da personalidade dos alunos, e o desenvolvimento pessoal e profissional das professorasestagiárias.

A criatividade foi de extrema importância para a prática na escola, porém só conseguimos ser criativas a partir do momento em que levamos em consideração a subjetividade dos alunos. Criar a partir das necessidades dos alunos é enxergá-los como o centro, como um ser de possibilidades e responsabilidade. Esse é o caminho para a construção de uma relação intersubjetiva e, conseqüentemente, uma relação de aprendizagem.

Ressalta-se que só é possível atingir os alunos como um todo quando, inicialmente, atingimos a nós mesmos. É claro que é muito difícil se desligar de valores e práticas tradicionais, devido à resistência que temos frente às mudanças, mas o resultado é compensatório.

Desta forma, é possível unir os princípios gestálticos à pedagogia, melhorando cada vez mais a qualidade do ensino e, conseqüentemente, a aprendizagem. Os métodos e princípios gestálticos podem ser utilizados para alcançar tanto objetivos tradicionais, quanto novos. 
A partir dessa vivência conclui-se que antes de trabalhar com os alunos, deve-se primeiramente trabalhar o novo método pedagógico com os professores e coordenadores, pois a Gestaltpedagogia exige, uma mudança no comportamento do professor, que conseqüentemente refletirá na mudança de comportamento dos alunos, pais, funcionários e do sistema escolar como um todo.

No mundo contemporâneo onde a educação é de suma importância para o desenvolvimento do indivíduo, ela não realiza toda sua potencialidade, pois nem toda instituição de ensino compreende que educar compete em ajudar o educando a descobrir a si mesmo. Cada ser humano traz em si alguém desconhecido, contendo a melhor parte de si mesmo, que quer se manifestar, exprimir-se e se realizar. É alguém que ainda não é, mas desde sempre foi. Para que aconteça o desenvolvimento do aluno é necessária a formação e a competência de bons educadores.

\section{Referências Bibliográficas}

Bicudo, M.A.V. (1999). A contribuição da fenomenologia à educação. Em Bicudo, M.A.V. \& Cappelletti, I. (Orgs.). Fenomenologia, uma visão abrangente da educação [p. 11-51]. São Paulo: Olho D’água.

Burow, O-A. \& Scherpp, K. (1985). Gestaltpedagogia - um caminho para a escola e a educação. São Paulo: Summus.

Costa, V.E.S.M. (2002). A relação professor-aluno a partir da Gestaltpedagogia: a intersubjetividade como elemento significativo para a aprendizagem. Dissertação de Mestrado, Universidade Católica de Goiás, Goiânia, Goiás.

Dartigues, A. (2005). O que é a fenomenologia? São Paulo: Centauro

Ferreira, R.M. (1993). Sociologia da educação. São Paulo: Moderna.

Libaneo, J.C. (1985). Democratização da escola pública: a pedagogia crítica-social dos conteúdos. São Paulo: Loyola.

Mello, G.N. (2000). Formação inicial de professores para a educação básica: uma (re)visão radical. São Paulo Perspectiva. São Paulo, v. 14, n. 1, p. 98-110.

Perls, F. (1977). A Abordagem gestáltica e testemunha ocular da terapia. Rio de Janeiro: Zahar

Perls, F.; Hefferline, R. \& Goodman, p. (1997). Gestalt-Terapia. São Paulo: Summus.

Polster E. \& Polster, M. (1979). Gestalt Terapia Integrada. Belo Horizonte: Interlivros, 1979.

Ribeiro, J.P. (1985). Gestalt-terapia: refazendo um caminho. São Paulo: Summus

Ribeiro, J.P. (1994). Gestalt-terapia, o processo grupal - uma abordagem fenomenológica da teoria do campo e holística. São Paulo: Summus
Juliana Arrais de Morais Moreira - Graduanda de Psicologia pela Universidade Católica de Goiás. Email: juarrais@hotmail.com.

Ludymila Pimenta Ferreira - Graduanda de Psicologia pela Universidade Católica de Goiás. Email: ludymilapimenta@gmail.com.

Virginia Elizabeth Suassuna Martins Costa - Psicóloga, Gestaltterapeuta, Professora do Departamento de Psicologia da Universidade Católica de Goiás (UCG). Professora e supervisora do Instituto de Treinamento e Pesquisa em Gestalt-terapia de Goiânia (ITGT), Mestre em Educação pela Universidade Católica de Goiás (UCG) e Doutoranda em Ciências da Saúde, pela Universidade de Brasília (UnB), em convênio com a Universidade Federal de Goiás (UFG). E-mail: itgt@gestaltterapia.com.br.

Recebido em 23.08.2006 Primeira Decisão Editorial em 20.09.2006 Segunda Decisão Editorial em 06.11.06 Versão Final em 16.02.07 Aceito em 30.07.07 